\title{
PENGARUH E-COMMERCE, TARIF PAJAK TERHADAP PENGGELAPAN PAJAK
}

\author{
Dewi Kusuma Wardani ${ }^{1}$, Puji Rahayu ${ }^{2}$ \\ Fakultas Ekonomi Universitas Sarjanawiyata Tamansiswa Yogyakarta ${ }^{1,2}$ \\ dewifeust@gmail.com ${ }^{1}$ Rahayupuij87@gmail.com ${ }^{2}$
}

\begin{abstract}
This study aims to examine the effect of E-commerce and Tax Rates on Tax Evasion. The data used are primary data. The method used is multiple regression analysis. The sampling technique used in this study was convinence sampling and 102 data samples. Regression test results show that tax rates affect tax evasion, while E-commerce do not affect tax evasion.

Keywords: E-commerce and Tax Rates

Abstrak

Penelitian ini bertujuan untuk menguji pengaruh E-commerce danTarif Pajak terhadap Penggelapan Pajak. Data yang digunakan adalah data primer. Metode yang digunakan adalah menggunakan analisis regresi berganda. Teknik sampling yang digunakan dalam penelitian ini adalah convinence sampling dan diperoleh 102 sampel data. Hasil uji regresi menunjukkan bahwa Tarif Pajak berpengaruh terhadap penggelapan pajak, sedangkan E-commerce tidak berpengaruh terhadap penggelapan pajak.
\end{abstract}

Kata kunci: E-commerce dan Tarif Pajak

\section{PENDAHULUAN}

Pajak merupakan kontribusi wajib kepada negara yang terutang oleh orang pribadi atau badan yang bersifat memaksa berdasarkan undang-undang dengan tidak mendapatkan imbalan secara langsung dan digunakan untuk keperluan negara bagi sebesar-besarnya kemakmuran rakyat (Undang-Undang Nomor 28 tahun 2009). Negara akan berkembang apabila masyarakat sadar akan membayar pajak.

Tabel di bawah ini menunjukan bahwa pendapatan dari sektor pajak sampai saat ini menjadi penyumbang pendapatan negara terbesar.

Tabel 1

Presentase Realisasi Penerimaan Pajak Tahun 2014-2018

\begin{tabular}{lccccc} 
& & & \multicolumn{2}{c}{ (dalam triliun rupiah) } \\
\hline \multicolumn{1}{c}{ Tahun } & $\mathbf{2 0 1 4}$ & $\mathbf{2 0 1 5}$ & $\mathbf{2 0 1 6}$ & $\mathbf{2 0 1 7}$ & $\mathbf{2 0 1 8}$ \\
\hline Target & $1.072,37$ & $1.294,26$ & $1.355,20$ & $1.283,57$ & 1.424 \\
Realisasi & 981,83 & $1.060,83$ & $1.105,81$ & $1.151,10$ & $1.315,9$ \\
Persentase & $91,56 \%$ & $81,96 \%$ & $81,60 \%$ & $89,68 \%$ & $92 \%$ \\
\hline
\end{tabular}

Sumber : (Laporan Kinerja Direktorat Jendral Pajak, 2018)

Berdasarkan tabel diatas, terlihat bahwa dalam penerimaan pajak pada setiap tahunnya mengalami kenaikan dan penurunan. Kementrian Keuanagan menyatakan bahwa penerimaan pajak hingga Desember 2018 hanya Rp 1.315,9 trilliun dari target Rp 1.424 trilliun. Hal ini membuat Indonesia mengalami shortfall atau tidak pernah mencapai target (tirto.id, 2019). Faktor penyebab target penerimaan pajak tidak tercapai yaitu masih banyak masyarakat yang memang masih enggan membayar pajaknya dan tarif yang tinggi mendorong masyarakat untuk melakukan penggelapan pajak (CNBC Indonesia, 2019a). Direktur Jendral Pajak juga menyatakan bahwa banyak pelaku bisnis online atau e-commerce yang memiliki penghasilan diatas Rp 4,8 milliar per tahun tidak patuh membayar pajak, baik berupa Pajak Penghasilan (PPh) maupun Pajak Pertumbuhan Nilai (PPN). Penyebabnya karena pelaporan pajak di Indonesia menggunakan self assessment system (CNBC Indonesia, 2019).

Pada penelitian ini penelitian ini ingin mengetahui seberapa tinggi penggelapan pajak di Indonesia. Alasanya karena jumlah wajib pajak yang sudah melaporkan SPT (Surat Pemberitahuan Tahunan) baru mencapai 4,7 wajib pajak. Angka tersebut baru mencapai $25,6 \%$ dari total wajib pajak yang terdaftar di otoritas pajak dan yang wajib melaporkan SPT sepanjang tahun 2018 sebanyak 18,3 juta wajib pajak. Perbedaan 
penelitian ini dengan penelitian sebelumnya adalah penambahan variabel independen yaitu variabel ecommerce yang dikombinasikan dengan variabel dependen yaitu penggelapan pajak karena penelitian mengenai hal ini masih jarang diteliti di Indonesia.

\section{TINJAUAN PUSTAKA / KAJIAN TEORITIS \\ Theory of Planned Behavior (TPB)}

Berdasarkan Theory of Planned Behavior, ketentuan perpajakan dapat dipatuhi seseorang apabila didalam diri individu tersebut memiliki intention (niat). Niat untuk berperilaku dipengaruhi oleh tiga faktor, yaitu sikap terhadap perilaku, norma subjektif dan kontrol perilaku yang dipersepsikan. Teori ini menjelaskan bahwa adanya niat untuk berperilaku dapat menimbulkan perilaku yang ditampilkan oleh individu.

Theory of Planned Behavior membagi tiga macam alasan yang dapat mempengaruhi tindakan yang diambil oleh individu, pertama behavioral belief (keyakinan perilaku) yaitu keyakinan akan hasil dari suatu perilaku, kedua normatif belief (keyakinan normatif) yaitu lingkungan individu yang mempengaruhi perilaku ketiga control belief (keyakinan kontrol) yaitu sikap terhadap perilaku dapat diartikan bahwa keyakinan atau pemahaman setiap wajib pajak atas mekanisme pembayaran pajak dan manfaat yang akan di terima serta anggapan wajib pajak terhadap perubahan dari penyederhanaan tarif pajak. Kontrol perilaku yaitu dengan dikenakan sanksi pajak bagi siapa saja yang melanggar aturan perpajakan. Hal tersebut yang menyebabkan timbulnya niat wajib pajak untuk bertindak patuh atau taat (Ajzen, 2011).

Apabila theory of planned behavior dikaitkan dengan biaya kepatuhan, maka seorang individu yang menanggung biaya kepatuhan yang besar dan memberatkan akan cenderung melakukan penggelapan pajak. Sebaliknya, apabila biaya kepatuhan yang ditanggung tidak terlalu memberatkan, maka individu akan cenderung menghindari penggelapan pajak (Suminarsasi, 2012).

\section{Penggelapan Pajak}

Rahman, (2013) menyatakan bahwa penggelapan pajak mengacu pada tindakan yang tidak benar yang dilakukan oleh wajib pajak mengenai kewajiban dalam perpajakan. Mardiasmo, (2011) mendefinisikan bahwa penggelapan pajak (tax evasion) merupakan suatu usaha yang dilakukan wajib pajak dengan cara meringankan beban pajak yang melanggar undang-undang. Penggelapan pajak ini dilakuakan dengan cara ilegal. Permatasari, (2013) menyatakan bahwa penggelapan pajak merupakan cara wajib pajak meminimalisir atau bahkan menghapus jumlah pajak yang seharusnya dibayarkan dan melanggar peraturan perundang-undangan. Pelanggaran pajak dilakukan untuk menghindari pembayaran pajak terutang. Penggelapan pajak sering terjadi akibat lemahnya peraturan atau hukum di Indonesia, sehingga para pelaku tidak memiliki efek jera terhadap kejahatan yang dilakuakan. Tarif pajak yang terlalu tinggi biasanya memicu wajib pajak untuk melakuakan penggelapan pajak.

\section{E-commerce}

Nirmala \& Musyafa, (2017) menyatakan bahwa e-commerce memiliki arti yang sangat luas yaitu penggunaan jaringan komputer yang mampu meningkatkan kinerja sebuah organisasi, meningkatkan pendapatan serta meningkatkan pangsa pasar sehingga permintaan pelanggan dapat dilakuakan dengan cara pemesanan online. Secara singkat, e-commerce melibatkan penggunaan teknologi informasi untuk meningkatkan komunikasi transaksi dengan seluruh pelanggan, pemasok pemerintah regulator, manajer, karyawan, dan masyarakat pada umumnya. Wahyuni, (2011) menyatakan bahwa e-commerce juga bisa disebut dengan pemasangan iklan dan cara berjualan di internet dengan pelayanan terbaik menggunakan web shop 24 jam untuk seluruh pelanggannya.

Irmawati, (2011) menyatakan bahwa ada beberapa jenis e-commerce, yaitu Business to consumer (B2C), Business to business (B2B), Consumer to consumer (C2C), Business to employee (B2E), E-Government dan Mobile Commerce (M-Commerce). Putra dkk, (2017) menyatakan bahwa e-commerce berkembang melalui sosial media. Sosial media yang biasnaya digunakan untuk sarana pertemanan atau pertukaran informasi, sekarang media sosial seperti facebook, twitter, instagram, whatsapp dan sebagainya menjadi salah satu trend baru bagi pebisnis online.

\section{Tarif Pajak}

Tarif merupakan jumlah yang harus dibayar oleh wajib pajak sesuai dengan penghasilan wajib pajak. Akibat tarif pajak yang tinggi (tergantung besarnya penghasilan), jika ada perubahan penghasilan maka 
besarnya pajak terutang juga akan berubah jumlahnya (Lazuardini \& Priyono, 2015). Tarif pajak merupakan dasar ketentuan jumlah (rupiah) pajak yang seharusnya dibayar oleh wajib pajak sesuai dengan dasar pengenaan pajak kepada obyek pajak (Amirudin \& Sudirman, 2012). Peraturan Pemerintah No. 23 tahun 2018, menjelaskan bahwa wajib pajak orang pribadi atau badan dengan penghasilan tidak termasuk jasa sehubungan dengan pekerja bebas, dengan peredaran bruto tidak melebihi 4,8 milliar rupiah dalam satu tahun pajak dikenakan tarif 0,5\% yang bersifat final. Resmi, (2017) menyatakan bahwa tarif pajak dibagi menjadi tiga macam yaitu:

1. Tarif Tetap

Tarif tetap merupakan tarif dengan jumlah dan angka tetap, berapapun besarnya dasar pengenaan pajak.

2. Tarif Proposional (sebanding)

Tarif proposional yaitu tarif berupa presentase tertentu yang sifatnya tetap terhadap berapapun dasar pengenaan pajaknya.

3. Tarif Progresif (meningkat)

Tarif progresif yaitu tarif pajak yang presentasenya menjadi dasar meningkatnya pengenaan pajak. Tarif pajak progresif dibag menjadi tiga macam yaitu tarif progresif proporsional, tarif progresif-progresif, tarif progresif degresif dantarif degresif (menurun)

\section{Penelitian Terdahulu}

Penelitian terdahulu dapat diuraikan dalam tabel matrik sebagai berikut

Tabel 2

Penelitian terdahulu

\begin{tabular}{|c|c|c|c|}
\hline No. & Peneliti & Judul & Hasil Penelitian \\
\hline 1. & Basu, (2003) & $\begin{array}{l}\text { Tax action of Electronic } \\
\text { Commerce }\end{array}$ & $\begin{array}{l}\text { Tindakan pajak berpengaruh positif terhadap } \\
\text { e-commerce }\end{array}$ \\
\hline 2. & $\begin{array}{l}\text { Zhongquan, } \\
\text { (2012) }\end{array}$ & $\begin{array}{l}\text { Tax evasion in E-commerce from } \\
\text { the perspective of China }\end{array}$ & $\begin{array}{l}\text { Barang dagangan digital, aset tidak berwujud } \\
\text { dan layanan online berpengaruh positif } \\
\text { terhadap penggelapan pajak. }\end{array}$ \\
\hline 3. & Jain, (2013) & $\begin{array}{l}\text { Tax Evasion a Dark Side of E- } \\
\text { Commerce }\end{array}$ & $\begin{array}{l}\text { Penggelapan pajak berpengaruh positif } \\
\text { terhadap e-commerce }\end{array}$ \\
\hline 4. & $\begin{array}{l}\text { Allingham dan } \\
\text { Sandmo, (2009) }\end{array}$ & $\begin{array}{l}\text { Income Tax Evasion: A } \\
\text { Theoretical Analysis }\end{array}$ & $\begin{array}{l}\text { Penggelapan pajak berpengaruh positif } \\
\text { terhadap pendapatan negara, }\end{array}$ \\
\hline 5. & Fisman, (2011) & $\begin{array}{l}\text { Tax Rates and Tax Evasion: } \\
\text { Evidence from "Missing Imports" } \\
\text { in China } \\
\text { Raymond }\end{array}$ & $\begin{array}{l}\text { Tarif pajak berpengaruh positif terhadap } \\
\text { penggelapan pajak. celah penggelapan } \\
\text { pajak di tiongkok ini sangat berkorelasi } \\
\text { dengan tarif pajak. }\end{array}$ \\
\hline 6. & $\begin{array}{l}\text { Christensen, } \\
\text { (2004) }\end{array}$ & $\begin{array}{l}\text { Tax avoidance, tax competition } \\
\text { and globalisation: making tax } \\
\text { justice a focus for global activis. }\end{array}$ & $\begin{array}{l}\text { Penggelapan pajak berpengaruh positif } \\
\text { terhadap keadilan, penggelapan pajak yang } \\
\text { sangat agresif membuat pemerintah terlibat } \\
\text { dalam persaingan pajak. }\end{array}$ \\
\hline 7. & Sasmito, (2017) & $\begin{array}{l}\text { Pengaruh Tarif Pajak, Keadilan } \\
\text { Sistem Perpajakan,Teknologi dan } \\
\text { Informasi Perpajakan Terhadap } \\
\text { Penggelapan Pajak. }\end{array}$ & $\begin{array}{l}\text { Variabel tarif pajak secara signifikan tidak } \\
\text { memiliki pengaruh terhadap penggelapan } \\
\text { pajak. Keadilan Sistem Perpajakan, } \\
\text { teknologi dan informasi perpajakan secara } \\
\text { signifikan memiliki pengaruh terhadap } \\
\text { penggelapan pajak. }\end{array}$ \\
\hline 8. & $\begin{array}{l}\text { Permatasari, } \\
\text { (2013) }\end{array}$ & $\begin{array}{l}\text { Minimalisasi Tax Evasion Melalui } \\
\text { Tarif Pajak, Teknologi dan } \\
\text { Informasi Perpajakan, dan } \\
\text { ketetapan } \\
\text { Pengeluaran Pemerintah }\end{array}$ & $\begin{array}{l}\text { Tarif pajak berppengaruh positif signifikan } \\
\text { terhadap tax evasion. Hasil pengujian } \\
\text { variabel teknologi dan informasi perpajakan } \\
\text { menunjukan adanya indikasi nilai yang } \\
\text { negatif, keadilan sistem perpajakan } \\
\text { berpengaruh negatif signifikan terhadap tax } \\
\text { evasion, ketetapan pengalokasian } \\
\text { pengeluaran pemerintah berpengaruh }\end{array}$ \\
\hline
\end{tabular}




\begin{tabular}{|c|c|c|c|}
\hline & & & negatif dan bersifat signifikan. \\
\hline 9. & $\begin{array}{l}\text { Amirudin dan } \\
\text { Sudirman, } \\
\text { (2012) }\end{array}$ & $\begin{array}{l}\text { Pengaruh sosialisasi perpajakan, } \\
\text { tarif pajak, dan pemahaman } \\
\text { perpajakan terhadap kepatuhan } \\
\text { wajib pajak }\end{array}$ & $\begin{array}{l}\text { Sosialisasi perpajakan, tarif pajak dan } \\
\text { pemahaman perpajakan berpengaruh positif } \\
\text { terhadap kepatuhan wajib pajak dan tarif } \\
\text { pajak. }\end{array}$ \\
\hline 10. & Wahyuni, (2011) & $\begin{array}{l}\text { Dampak e-commerce dan } \\
\text { pemeriksaan pajak terhadap } \\
\text { penerimaan pajak pada KPP } \\
\text { Pratama Kota Bandung }\end{array}$ & $\begin{array}{l}\text { Dampak e-commerce pada KPP Pratama } \\
\text { Kota Bandung berpengaruh terhadap } \\
\text { penerimaan pajak pada KPP Pratama Kota } \\
\text { Bandung. }\end{array}$ \\
\hline
\end{tabular}

\section{METODE PENELITIAN}

Penelitian ini menguji pengaruh e-commerce dan tarif pajak terhadap penggelapan pajak. Sifat penelitian ini adalah penelitian kuantitatif. Menurut Kuncoro, (2013) metode penelitian kuantitatif adalah pendekatan ilmiah terhadap pengambilan keputusan manajerial dan ekonomi. Penelitian ini terdiri dari perumusan masalah, menyusun model, mendapatkan data, mencari solusi, menguji solusi, menganalisa hasil dan mengimplementasikan hasil.

Penelitian ini menggunakan populasi wajib pajak yang menggunakan media sosial (internet). Sampel dalam penelitian ini berjumlah 102 responden wajib pajak yang memiliki bisnis online, karena penelitian ini dilakuakan dengan menggunakan kuesioner yang dilakukan melalui google form. Peneliti akan membagikan link kepada responden yang memiliki bisnis online melalui sosial media seperti e-mail, whatsapp, instagram, twitter dan facebook. Pengambilan sampel atas responden dilakukan dengan metode convinience sampling. Convinience sampling yaitu prosedur untuk mendapatkan data sampel sesuai keinginan peneliti.

Dalam metode analisis data, peneliti menggunakan analisis regresi linier berganda. Langkah-langkah analisi sebgaai berikut:

1. Uji kualitas data
a. Uji Validitas
b. Uji Reliabelitas

2. Statistik Deskriptif

3. Uji asumsi klasik
a. Uji normalitas data
b. Uji multikolinieritas
c. Uji heterodastisitas

4. Teknik analisis data
a. Uji F
b. Analisis koefisien determinasi $\left(\mathrm{R}^{2}\right)$
c. Uji parsial (Uji t)

\section{HASIL dan PEMBAHASAN PENELITIAN}

Pada penelitian ini, peneliti menggunakan data primer yang diperoleh dari jawaban responden melalui kuesioner menggunakan google from. Penelitian ini dilakukan terhadap 102 responden yaitu responden yang memiliki bisnis online. Berdasarkan uji validitas dan realibilitas, pengujian ini menunjukan bahwa seluruh pertanyaan valid dan realibel. Berdasarkan uji normalitas maka didapatkan hasil bahwa semua data terdistribusi normal. Berdasarkan uji multikolinieritas menunjukan bahwa penelitian ini bebas dari masalah multikolinieritas. Hal ini dibuktikan dengan nilai tolerance $>0,10$ dan nilai variance inflation factor (VIF) $<10$. Uji asumsi klasik yang terakhir adalah uji heteroskesdastisitas maka penelitian ini dinyatakan lolos dari masalah heteroskesdastisitas. Hal ini didukung dengan variabel yang berada diatas 0,05 . sebagai berikut:

Setelah lolos asumsi klasik, langsung diregresi pada SPSS. Persamaan regresi dihasilkan output SPSS 
Tabel 3

Hasil Persamaan Regresi dan Uji Hipotesis Parsial

\begin{tabular}{|c|c|c|c|c|c|c|}
\hline \multirow{2}{*}{\multicolumn{2}{|c|}{ Model }} & \multicolumn{2}{|c|}{ Unstandardized Coefficients } & \multirow{2}{*}{$\begin{array}{c}\begin{array}{c}\text { Standardized } \\
\text { Coefficients }\end{array} \\
\text { Beta }\end{array}$} & \multirow[b]{2}{*}{$\mathrm{t}$} & \multirow[b]{2}{*}{ Sig. } \\
\hline & & B & Std. Error & & & \\
\hline \multirow[t]{3}{*}{1} & (Constant) & -11.154 & 6.437 & & -1.733 & .086 \\
\hline & E-commerce & .296 & .322 & .079 & .920 & .360 \\
\hline & Tarif Pajak & 1.177 & .168 & .604 & 7.022 & .000 \\
\hline
\end{tabular}

Berdasarkan hasil penelitian ini dapat disimpulkan bahwa e-commerce berpengaruh positif terhadap penggelapan pajak. Hasil uji hipotesis 1 menyimpulkan bahwa e-commerce tidak berpengaruh terhadap penggelapan pajak. Hasil uji hipotesis menyatakan bahwa nilai t hitung 0,920 lebih kecil dari t tabel dan tingkat signifikansinya 0,360 , berdasarkan hasil data tersebut, maka e-commerce tidak berpengaruh terhadap penggelapan pajak. Dengan demikian $\mathrm{H}_{1}$ tidak berpengaruh.

Hasil pengujian ini menunjukan bahwa e-commerce tidak berpengaruh terhadap penggelapan pajak yang dapat disebabkan oleh tingkat kepatuhan yang rendah, kesulitan wajib pajak untuk melaporkan pajaknya dan kurangnya bantuan sistem perpajakan yang ada. Pendapat ini diperkuat dari jawaban responden atas pernyataan bahwa transaksi bisnis online dengan banyak pilihan fitur dan fasilitas cara pembayaran yang ditawarkan yang mana mayoritas responden menjawab setuju, yang artinya wajib pajak sudah mengakui bahwa transaksi yang digunakan e-commerce sudah baik namun, hal tersebut tidak mempengaruhi wajib pajak untuk melakukan penggelapan pajak. Theory of Reasoned Action (TRA) menjelaskan bahwa perilaku seseorang adalah perkiraan dari intensitas dan tindakannya, dimana seseorang akan menggunakan sistem informasi dan teknologi informasi jika hal tersebut bermanfaat dan meningkatkan kinerjanya. Berkembangnya teknologi saat ini yang memudahkan pelaku bisnis online untuk mempromosikan barang atau jasa melalui internet yang diharapkan dapat memberikan kontribusi bagi perekonomian Indonesia terutama sektor pajak (Ajzen (2011, dikutip dari Nurhayati, 2019).

Hasil penelitian ini sejalan dengan penelitian Utomo (2012) yang menyatakan bahwa e-commerce tidak berpengaruh terhadap penggelapan pajak. Hasil penelitian ini tidak sejalan dengan penelitian yang dilakukan oleh Aprilia (2014) dan Wahyuni (2011) menyatakan bahwa e-commerce berpengaruh terhadap penggelapan pajak.

Hipotesis 2 yang diajukan dalam penelitian ini adalah tarif pajak berpengaruh positif terhadap penggelapan pajak. Hasil uji hipotesis 2 menyimpulkan bahwa tarif pajak berpengaruh positif secara signifikan terhadap penggelapan pajak. Hal ini dibuktikan dengan hasil t hitung 7.022 lebih besar dari t tabel dan tingkat signifikansinya 0,000 . Berdasarkan hasil tersebut maka $\mathrm{H}_{2}$ berpengaruh.

Hasil pengujian ini memberikan bukti bahwa tarif pajak yang tinggi akan mempengaruhi penggelapan pajak. Pendapat ini diperkuat dengan hasil analisis jawaban responden atas pernyataan bahwa wajib pajak ingin membayar pajak dengan meminimalkan pendapatan yang mana mayoritas jawaban responden menjawab setuju, yang artinya, bahwa besarnya tarif pajak mempengaruhi kemampuan wajib pajak dalam membayar pajak, hal tersebut menjadikan celah wajib pajak untuk melakukan penggelapan pajak. Hal ini sesuai dengan Theory of planned behavior yang menyatakan bahwa selain sikap terhadap tingkah laku dan norma-norma subjektif, individu juga mempertimbangkan kontrol tingkah laku yang dipersepsikan yaitu kemampuan wajib pajak untuk melakukan penyederhanaan tarif pajak.

Hasil penelitian ini sejalan dengan hasil Penelitian terkait tarif pajak yang diteliti Permatasari (2013) dan Kurniawati \& Toly (2014) menyatakan bahwa tarif pajak berpengaruh positif terhadap penggelapan pajak, sedangkan hasil penelitian ini tidak sejalan dengan penelitian Lazuardini \& Priyono (2015) dan Mir'atusholihah dkk (2013) menyatakan bahwa tarif pajak tidak berpengaruh terhadap penggelapan pajak. 


\section{SIMPULAN DAN SARAN}

\section{KESIMPULAN}

Penelitian ini dilakukan terhadap 102 responden yaitu responden yang memiliki bisnis online. Berdasarkan hasil penelitian ini dapat disimpulkan bahwa tarif pajak berpengaruh positif terhadap penggelapan pajak. $E$ commerce dan keadilan pajak tidak berpengaruh terhadap penggelapan pajak.

Hasil penelitian ini sejalan dengan penelitian Permatasari (2013) dan Kurniawati \& Toly (2014) menyatakan bahwa tarif pajak berpengaruh terhadap penggelapan pajak, sedangkan penelitian ini bertolak belakang dengan Lazuardini \& Priyono, (2015) dan Mir'atusholihah dkk, (2013) menyatakan bahwa tarif pajak tidak berpengaruh terhadap penggelapan pajak. Hasil penelitian Utomo, (2012) menyatakan bahwa e-commerce tidak berpengaruh terhadap penggelapan pajak, dan hasil penelitian ini bertolak belakang dengan penelitian Aprilia, (2014) dan Wahyun, (2011) yang menyatakan bahwa e-commerce berpengaruh terhadap penggelapan pajak.

\section{SARAN}

1. Bagi Direktorat Jendral Pajak

a. Direktorat Jendral Pajak hendaknya memperhatikan dan mempertimbangkan kembali jika ada peraturan tarif pajak yang baru, sehingga dapat diterima dengan baik oleh masyarakat dan masyarakat dapat mematuhi peraturan yang ada di Indonesia serta terhindar dari penggelapan pajak.

b. Direktorat Jendral Pajak hendaknya lebih memperhatikan dan meningkatkan kopetensi yang dimiliki oleh pebisnis online yang ada di Indonesia. Contoh kegiatan yang dapat dilakukan untuk meningkatkan kopetensi pebisnis online adalah dengan mengadakan sosialisasi pajak secara mendasar kepada kalangan pelajar mengingat saat ini pebisnis online bisa dilakukan oleh semua kalangan bahkan sebagian besar pelajar saat ini menjadi pebisnis online. Hal ini perlu dilakukankarena melalui program ini wajib pajak, khususnya pebisnis online akan mendapatkan pengetahuan dan kesadaran yang akan bermanfaat untuk meningkatkan penerimaan pajak.

2. Bagi Peneliti Selanjutnya

a. Diharapkan penelitian selanjutnya dapat menggunakan variabel independen lain selain yang digunakan pada penelitian ini, baik dengan cara penggantian variabel atau penambahan variabel. Variabel independen lain yang dapat digunakan adalah hukum perpajakan yang berlaku di Indonesia.

b. Sumber data untuk penelitian selanjutnya dapat menggunakan wawancara agar data yang didapat dari responden lebih detail dan mendalam.

\section{DAFTAR PUSTAKA}

Ajzen, I. (2011). The theory of planned behaviour : Reactions and reflections, (June).

Allingham, M. G., \& Sandmo, A. (2005). Income Tax Evasion: A Theoretical Analysis. Physical Review E - Statistical, Nonlinear, and Soft Matter Physics

Amirudin, \& Sudirman. (2012). Perpajakan Pendekatan Teori dan Praktik di Indonesia. Jakarta: Salemba Empat Dua Media.

Aprilia, et al. (2014). Penanganan dan pengawasan perpajakan dalam rangka intensifikasi di E-Commerce (Studi Pada Kantor Pelayanan Pajak Pratama Malang Selatan).

Basu, S. (2003). Tax action of Electronic Commerce. Chinese Journal of Clinical Rehabilitation.

Christensen, J. (2004). Tax Avoidance, Tax Competition and Globalisation: making tax justice a focus for global activism. Global Tax Workshop.

CNBC Indonesia. (2019a). Baru 25\% Wajib Pajak yang Lapor SPT, Anda Sudah? recertived to https://www.cnbcindonesia.com/news/20190311134322-4-59867/baru-25-wajib-pajak-yang-lapor-spt-anda-sudah

CNBC Indonesia. (2019b). Karena Pajaknya Tak Beres, Belanja di Toko Online Lebih Murah. Recertived to https://www.cnbcindonesia.com/news/20190114153057-4-50561/karena-pajaknya-tak-beres-belanja-di-toko-onlinelebih-murah

Lazuardini, H. J. S., \& Priyono, A. A. (2015). Pengaruh Pemahaman Peraturan Perpajakan, Tarif Pajak dan Sanksi Pajak Terhadap Kepatuhan Wajib Pajak UMKM (Studi Pada Wajib Pajak Orang Pribadi Yang Terdaftar di KPP Pratama Malang Selatan).

Fisman, R. (2011). Tax Rates and Tax Evasion: Evidence from "Missing Imports" in China. Journal of Political Economy. Irmawati, D. (2011). Pemanfaatan E-Commerce Dalam Dunia Bisnis. 
Jain, N. (2013). Evasion Pajak Dark Side of E-Commerce, (5), 16-18.

Kuncoro, M. (2013). Metode Riset untuk Bisnis \& Ekonomi Bagaimana Meneliti dan Menulis Tesis (Edisi 4). Jakarta: Erlangga.

Kurniawati, M., \& Toly, A. A. (2014). Analisis Keadilan Pajak, Biaya Kepatuhan, Dan Tarif Pajak Terhadap Persepsi Wajib Pajak Mengenai Penggelapan Pajak Di Surabaya Barat. Tax \& Accounting Review.

Laporan Kinerja Direktorat Jendral Pajak. (2017). Realisasi Penerimaan Pajak.

Mardiasmo. (2011). Perpajakan Edisi Revisi 2011. Yogyakarta: Andi.

Mir'atusholihah, Kumadji, S., \& Ismono, B. (2013). Pengaruh Pengetahuan Perpajakan, Kualitas Pelayanan Fiskus dan Tarif Pajak Terhadap Kepatuhan Wajib Pajak (Studi Pada Wajib Pajak UMKM di Kantor Pelayanan Pajak Pratama Malang. Jurnal Univeristas Brawijaya.

Nirmala, E., \& Musyafa, A. (2017). Modul E-commerce. (P. Oktavia, Ed.). Banten: UNPAM PRESS.

Nurhayati, N. (2019). Pengaruh Self Assesment System, E-commerce dan Keterbukaan Rekening Bank Terhadap Penghindaran Pajak.

Permatasari, I. ; herry L. (2013). Minimalisasi Tax Evasion Melalui Tarif, Teknologi dan Informasi Perpajakan, Keadilan Sistem Perpajakan, dan Ketepatan Pengalokasian Pengeluaran Pemerintah (Studi Empiris pada Wajib Pajak Orang Pribadi di Wilayah KPP Pratama Pekanbaru Senapelan).

Putra, S. S. C., Indraningrat, K., \& Halim, A. (2017). Persepsi Mahasiswa Terhadap E-commerce melalui Facebook di Kecamatan Sumbersari Kabupaten Jember. e-Journal Ekonomi Bisnis dan Akutansi.

Rahman, irma suryani. (2013). Pengaruh Keadilan, Sistem Perpajakan, Diskriminasi, Dan Kemungkinan Terdeteksi Kecurangan Terhadap Persepsi Wajib Pajak Meenai Etika Penggelapan Pajak. Journal of Chemical Information and Modeling.

Resmi, S. (2017). Perpajakan teori dan Kasus (10 ed.). Jakarta: Salemba empat.

Sasmito, G. G. (2017). Pengaruh tarif pajak, keadilan sistem perpajakan, teknologi dan informasi perpajakan terhadap penggelapan pajak.

Suminarsasi, W., \& Supriyadi. (2012). Pengaruh Keadilan, Sistem Perpajakan, dan Diskriminasi Terhadap Persepsi Wajib Pajka Mengenai Etika Penggelapan Pajak (Tax Evasion).

tirto.id. (2019). Penerimaan Negara 2018 Tembus Target, tapi Pajak Masih Shortfall. Recertived to https://tirto.id/penerimaan-negara-2018-tembus-target-tapi-pajak-masih-shortfall-ddeX

Utomo, E. M. (2007). Transaksi E-commerce Sebagai Potensi Penerimaan Pajak di Indonesia. Journal of Experimental Psychology: General.

Wahyuni, N. I. (2011). Dampak E-Commerce dan Pemeriksaan Pajak Terhadap Penerimaan Pajak Pada KPP Pratama Kota Bandung.

Zhongquan, Y. (2012). Tax Avoidance in E-Commerce from the Perspective of China, (February). 